immune polysaccharides from the organism described. The occurrence of toxins in cultures of the organism appeared to be doubtful. The epidemiology of the disease was discussed in seven papers. Polymorphism which occurs in African trypanosomes was compared with that met with in T. cruzi, and observations made on the nature of their evolutionary cycles. The session was concluded by the showing of a film dealing with methods of eradication of the tsetse fly, which transmits the disease in Portuguese Africa. On the same evening a meeting was held in the Brazilian Academy of Seiences from $9 \mathrm{p.m}$. until midnight, at which a paper was read on "Chagas as Protozoologist", and others on the metabolism, phylogeny and growth of the parasite. The following day was devoted to the pathology of acute and chronic eases of the disease in different parts of the South American continent, throughout which the virulence of the causative agent varies. Discussions took place on the myocardial, nervous, cerebrovascular and blood protein changes involved, as well as on the condition of megacolon and megacesophagus now believed to be causally related to the disease. Further papers on epidemiology dealt with animal reservoirs and with the feeding habits of domestic and wild types of reduviid bugs. The danger of blood transfusion as a means of spread was also dealt with. Prophylaxis was best effected by spraying the sites where the vector was found, along with general hygienic measures. Workers from different areas of South America, where the nature of the problem varies with the transmitting agent, contributed also on the following day. The different clinical forms and diagnosis of the disease, including that met with in congenital cases, were described in seven papers. At a special session the nature of the infection caused by Trypanosoma rangeli was described. This parasite was first described in 1920 by Tejera in Venezuela, where it infects Rhodnius prolixus, which is also the chief transmitter of $T$. cruzi there. The first forms were seen in human blood in Guatemala in 1946, and now 795 cases of infection have been described in Venezuela, chiefly in children, but the infection is not of serious character. At an evening session in the National Academy of Medicine further papers were read. On the last full working day of the congress, eighteen papers were read, chiefly on the relationship of cardiac and nervous disorders, including megacolon and megacesophagus, to Chagas's disease. Discussions also took place on chemotherapeutic agents, but the sad fact remains that no curative agent is known for this disease. A short ceremony took place during the morning at which a plaque, presented by the Argentinian delegation, to the memory of Carlos Chagas was unveiled.

On the same day a paper was read by Prof. Jean Coudert on the action of $T$. cruzi extracts on cancer cells, another by William Frye on antibiotics in tropical disease, and Rene Dubos gave a talk on general aspects of infection.

The final meoting on July 11 was devoted to round-table discussion of the subjects dealt with earlier in the woek. Resolutions were also submitted regarding the holding of another international congress within the next fow years, but no definite decisions were arrived at. During the week more than 150 papers were read. Two medals were struck to commemorate the congress, each with the head of Carlos Chagas on one side, but differing on the obverse side. The proceedings of this inspiring congress will be published in due course.

\section{J. D. Fulton}

\title{
SPECIAL CERAMICS
}

T HE challenge of temperature, which has inspired the metallurgist to some of his more notable developments, has in recent years been renewed and has been taken up by the ceramist, who is seeking materials of low creep resistance, high thermal shock resistance and high hot-strength to meet the demands of propulsion engineering, high-speed vehicles and nuclear engineering. The ceramist has for many years made his own special contribution to communications engineering, chiefly in the exploitation of oxide-type materials; the field of non-oxide materials remained largely unexplored, but it is now being opened up by the drive for new materials in other engineering applications. The British Ceramic Research Association has for the past five years had a small group devoted to these studies and has been working in close co-operation with various Service departments and industrial concerns. It was felt that some attempt to set up a forum for the exchange of ideas would be timely, and the outcome was a Symposium on Special Ceramies held at the Laboratories of the British Ceramic Research Association in Stokeon-Trent during July 13-15. About 150 delegates attended the symposium and seven countries were represented. The subject-matter of the symposium was divided into four sessions dealing with: (1) properties and structure, measurements; (2) preparation and properties of nitrides ; (3) preparation and properties of other non-oxides; and (4) furnaces, techniques, analysis, applications, etc.
After a welcome to the delegates by the chairman of the Association, Mr. E. James Johnson, and the director, Dr. A. T. Green, the deputy director, Dr. N. F. Astbury, gave an introductory lecture on the fields of application for new ceramic materials, and spoke of the special ceramies research programme of the British Ceramic Research Association, in which particular reference was made to boron nitride, a machinable dielectric capable of withstanding high temperatures, and to a new form of self-bonded silicon carbide and to silicon nitride. Both the latter materials are being actively studied in connexion with rocket engineering. The dependence of macroscopic properties on crystal structure and the trends observed in groups of materials of the same structure were discussed in a paper by Dr. S. N. Ruddlesden (British Ceramic Research Association), who illustrated her arguments by non-oxides such as silicon nitride and boron phosphide, the latter being a new compound of the III-V series of zinc-blende structures. Like silicon carbide, boron phosphide is very hard and it is a semiconductor with an energy gap of the order of $5 \mathrm{eV}$.

The greatest challenge that ceramics must face in meeting metals in their chosen field is the absence of ductility and their comparatively low breaking strain. The reply to this is being sought by a study of the properties of certain oxide crystals, and it was of special interest, therefore, that Dr. F. J. P. Clarke (U.K. Atomic Energy Authority, Harwell) was able 
to give an account of his experiments on the roomtemperature ductility of single crystals of magnesium oxide, together with his observation of slip bands and fracture starting at the intersection of these slip bands near a crystal face. Dr. Clarke discussed possible applications of his results to polyerystalline materials.

Methods of measuring thermal conductivity requiring much less time than traditional methods were described by Mr. T. W. Lindop (Morgan Crucible Co.), and Mr. R. P. Tye (National Physioal Labora. tory) contributed to the discussion with an account of an even more rapid ( $<1 \mathrm{~min}$.) comparator method. A simple apparatus for the measurement of creep at high temperature $\left(1,200^{\circ} \mathrm{C}\right.$.) was described in a paper by Messrs. N. L. Parr and G. F. Martin, read by Mr. D. M. Rae (Admiralty Materials Laboratory). Dr. Clarke ended the first session with a description of the effect of reactor irradiation on ceramic materials, which aroused some lively discussion on the damage mechanism and the neutron energies causing most damage.

Silicon nitride is a hard, very strong material (the modulus of rupture at $1,200^{\circ} \mathrm{C}$. is of the order of $18,000 \mathrm{lb} . / \mathrm{sq}$. in.) which can be made into shapes of accurate dimensions by nitriding pressed siliconpowder, since no contraction occurs during the firing. Its preparation, its properties as an engineering material (it possesses very good thermal shock resistance and satisfactory resistance to creep) and its microstructure were described by Messrs. N. L. Parr, G. F. Martin and E. R. W. May (Admiralty Materials Laboratory). In the subsequent discussion, Mr. P. Popper (British Ceramic Research Association) showed photographs of some intriguing spiral 'whiskers' of silicon nitride. A new hexagonal form of $\mathrm{Be}_{3} \mathrm{~N}_{2}$ was deseribed by Drs. A. Rabenau and P. Eckerlin (Philips, Aachen), who had studied the system $\mathrm{Be}_{3} \mathrm{~N}_{2}-\mathrm{Si}_{3} \mathrm{~N}_{4}$ and found two other compounds, $\mathrm{Be}_{4} \mathrm{SiN}_{4}$ and a wurtzite-type compound, $\mathrm{BeSiN}_{2}$.

There is a wide gap between organic plastic insulators, which can be easily shaped by moulding or machining but which cannot withstand high temperatures, and refractory insulators, which can withstand very high temperatures but are difficult to make to accurate dimensional tolerances. One material which helps to bridge this gap is boron nitride, a refractory insulator which can be easily machined, a property which is attributed to its layer lattice crystal structure, which resembles that of graphite, with which it is isosteric. It is not wetted by many molten metals and has a high electrical resistivity $\left(10^{6} \mathrm{ohm} \mathrm{cm}\right.$. at $1,300^{\circ}$ C. $)$ and high resistance to chemical attack. The preparation of boron nitride, its possible uses, the control of hot-pressing and stability by additions of 'impurities' were described by Dr. T. A. Ingles and Mr. Popper (British Ceramic Research Association). Other possible materials to bridge the gap are being sought in polymers which contain boron and nitrogen or phosphorus and nitrogen. The paper by Messrs. F. W. Ainger and I. M. Herbert (Plessey Research Laboratories) on the preparation of phosphorus-nitrogen compounds as non-porous solids was remarkable for the presentation of so much inorganic chemistry in the language of the organic chemist.

Knowledge of dissociation pressures is important in considering materials for high-temperature applications, and measurements of the dissociation pressures of metallic silicides and of silicon carbide were reported by Mr. P. Grieveson and Dr. C. B. Aleock (Imperial College of Science and Technology), who interpreted their results on a thermodynamic basis. A novel way of preparing an extremely strong, dense silicon carbide, without the need for hot-pressing, was described by Mr. P. Popper. The method involves heating a cold-pressed mixture of carbon and silicon carbide powder in an atmosphere of silicon vapour when, under appropriate conditions, a material is obtained with a density of $3.05 \mathrm{gm} . / \mathrm{cm} .^{3}$ (corresponding to 95 per cent crystallographic density) and a modulus of rupture at room temperature of the order of 30,000 lb./sq. in. Another silicide, $\mathrm{MoSi}_{2}$ described by Mr. J. B. Huffadine (Plessey Research Laboratories), has a very low electrical resistivity and is used in heating elements. It has a remarkably high oxidation resistance and an expansion coefficient substantially the same as alumina, from $0^{\circ}$ to $1,000^{\circ} \mathrm{C}$. It also adheres strongly to alumina if hot-pressed with this oxide, and it was suggested that composite $\mathrm{MoSi}_{2}-\mathrm{Al}_{2} \mathrm{O}_{3}$ pressings could provide useful electrical components.

The preparation and properties of calcium fluoride ware were described by Mr. P. Rado (Worcester Royal Porcelain Co.). Although this material has a very poor thermal shock resistance, it has found application as a crucible material for the reduction of metallic fluorides, particularly uranium fluoride.

Photoconductive materials have normally been used in the form of single crystals, but Drs. W. van Gool and J. G. van Senten (Philips, Eindhoven) showed that a polycrystalline aggregate of cadmium sulphide could be used as an element in photosensitive devices.

Throughout the symposium attention was repeatedly directed to the high-temperature techniques required in the preparation of special ceramies, and some of these were discussed in detail in the final session, which included three papers on furnace design. Dr. A. Z. Borucka (Metals Research, Ltd.) described the construction of a furnace to give a hot zone $\left(1,200^{\circ}\right.$ C.) of very uniform temperature by having the furnace windings split into several sections with the spacing of the windings graduated in each section. Dr. M. Cole and Dr. Borucka (Metals Research, Ltd.) described a novel replaceable heating element, consisting of a molybdenum heater encased in an alumina sheath through which hydrogen or another protective gas is passed. These elements can heat a furnace with a capacity of several cubic feet to $1,800^{\circ} \mathrm{C}$. in either oxidizing or reducing atmospheres, giving a uniform temperature distribution with no contamination of the furnace atmosphere. The construction and advantage of various types of carbon-tube furnace, that is to say, the simple tube, the single-ended, hairpin-cut tube and the spiral-cut tube, capable of operating at temperatures above $2,000^{\circ} \mathrm{C}$. in vacuo or in controlled atmospheres, were described by Mr. C. J. W. Baker (British Ceramic Research Association).

Many of the special ceramic materials cannot be melted under normal conditions, and so sintering cannot be used as a means of densification. The alternative technique is hot-pressing, but this has the disadvantage in general that only simple shapes can be produced without further machining. Dr. J. S. Jackson and Mr. P. F. Palmer (British ThomsonHouston Research Laboratories) described an apparatus designed for hot-pressing small specimens of refractory hard materials to high density in graphite 
dies heated by passing a high current through the walls. They reported the contraction of various carbides, borides and oxides as a function of temperature, and showed that reduction of particle size reduced the temperature needed for densification.

One of the difficulties of powder aggregation is the variation in density which may occur through the compact. This difficulty can be circumvented by isostatic pressing, and the use of a reversible gel, such as a polyvinyl polymer, as a mould material giving substantially true hydrostatic pressures up to 50 tons $/$ in. ${ }^{2}$ was described by $\mathrm{Mr}$. T. W. Penrice (Production Tool Alloy Co.). The technique is evidently applicable to quite complicated shapes.
The analyst's outlook on the new materials was touched upon in a paper by Mr. H. Bennett (British Ceramic Research Association) on the chemical determination of nitrogen in refractory nitrides, which posed many new problems. The final paper was a description by J. Peyssou (C.S.F., France) of the possible variations of properties of ceramic articles caused by variations in firing conditions and methods of manufacture.

The symposium concluded with a tour of the laboratories of the British Ceramic Research Association. The proceedings of the symposium are to be published by Heywood and Co. as a book, "Special Ceramics", which is being edited by Mr. P. Popper. N. F. Astbury

\section{SOLID STATE PHYSICS}

A CONFERENCE was held at Melbourne on "Solid State Physics" during August 17-21 under the auspices of the Australian Branch of the Institute of Physics. Grants from Australian industry, learned societies, government organizations and universities and support by the United States Government research authorities, the United Kingdom Atomic Energy Authority and the Canadian Government enabled several Americans, a Canadian and three Englishmen to attend. Other States of the Commonwealth of Australia and New Zealand were well represented.

The matter was drawn from across almost the whole range of this enormous subject, and one could hope that it might set a style of conference where the programme would be not so specialized that only a few experts could really benefit.

The programme opened with a day devoted to lowtemperature properties of metals and alloys. Precision lattice parameters, superconductivity and superfluidity, dislocation-phonon scattering and electron phonon drag effects were discussed. The changes of lattice parameter in bismuth on alloying set a challenge to the theorists, and the dislocation scattering of phonons seems still to be in error by a factor assessed as between three and seventy by one speaker.

Electron field emission, low-energy sputtering, epitaxial growth and dislocation barriers at surfaces served during the next day to remind those present just how little of the surfaces of solids is understood. The afternoon and following day were devoted to plasticity studies, when softening by adiabatic heating was used to explain the serrated load extension curves of iron at temperatures immediately above the brittle fracture region, as well as for aluminium at very low temperature. The dependence on orientation of work hardening and of slip-system geography in face-centred cubic metals were presented, and it was clearly the opinion of the majority that current theories are far too simple in their outlook. The Peierls-Nabarro force, its connexion with lattice friction, and the significance of the friction term in the hardening curves formed a recurrent theme in and out of the lecture room. Preliminary results indicate that reliable twin-fault densities may be obtained from the asymmetry of Bragg peaks and this may inject a little more knowledge of the deformed state. Measurements of the mechanical properties of the alkali metals at very low temperatures, along with optical microscope studies, have confirmed the X-ray evidence of shear transformations in sodium and lithium, and have brought to light a great sensitivity to structural details in the transformation of the crystalline aggregate.

On the third day attention was swung to optical properties of solids, with papers on soft X-ray studies of the light metals, infra-red and optical absorption in ionic crystals. Dielectric properties of doped alkali halides, evidence for aggregation of $F$ centres and new techniques and facts in luminescence studies were the subjects for the remainder of the day. The analysis of rare-earth spectra in crystals is getting steadily more detailed and very large-scale calculations are rapidly elucidating the details of interactions within the $f$ electron-shell.

The last day saw an interesting mixture of papers : the dreadful maze into which theoretical physicists lead each other when the anharmonic terms leading to thermal expansion are studied was on show, as was the theory of zone structure in liquids. Here some progress seemed to be made for the onedimensional model. The magnetic structure of metallic chromium and its alloys was discussed in terms of magnetic properties and neutron diffraction evidence. Then came the grand finale with one situation well on the way to elucidation and three well on the way to confusion. The ordering of $\alpha$-brass at temperatures of about $135^{\circ} \mathrm{C}$. has been most convincingly shown and will probably remove the few remaining anomalies in the properties of the $\alpha \mathrm{Cu}-\mathrm{Zn}$ phase in this temperature region. But in copper the first annealing observed after very low-temperature bombardment now occurs at only $7^{\circ} \mathrm{K}$., and the atomic processes involved get steadily more mysterious. Polycrystalline calcite or 'marble' plastically uni-axially compressed at high hydrostatic pressure, largely recovers its axial dimensions on release of the hydrostatic pressure. In lithium fluoride as well as silicon iron, plastic hardening seems to denote a drop in dislocation speed under a given stress, indicating an increase in dislocation viscosity-or is it a drop in effective stress ?

It was a stimulating conference, and those from overseas were impressed to find such a wealth of first-class work, enthusiasm and hospitality in this rapidly growing and developing continent of Australia.

W. M. LOMER 